- 研究报告・

\title{
云南哀牢山常绿榈叶林的空间分异及其影响因素
}

\author{
徐远杰 ${ }^{1}$ 林敦梅 ${ }^{2}$ 石 明 ${ }^{3}$ 谢妍洁 ${ }^{3}$ 王逸之 ${ }^{1}$ 管振华 $1^{*} \quad$ 向建英 ${ }^{1}$ \\ 1 (西南林业大学云南生物多样性研究院, 昆明 650224) \\ 2 (重庆大学三峡库区生态环境教育部重点实验室, 重庆 400044) \\ 3 (西南林业大学林学院, 昆明 650224)
}

\begin{abstract}
摘要: 理解物种丰富度在空间上的变化, 阐明植物群落组成对生境异质性的响应是群落生态学研究的核心议题之 一。与生境异质性有关的生态位分化对植物群落的多样性格局和物种分布具有重要影响。本文以分布在云南哀牢 山的 4 种常绿阔叶林为研究对象, 通过对 42 个森林样地的调查取样, 探讨了常绿阔叶林的群落分布和树种丰富度 在地形和土壤环境梯度上的变异。结果表明: 4 种常绿榈叶林的树种组成有显著的差异。季风常绿阔叶林的树种丰 富度极显著地高于其他 3 种类型; 中山湿性常绿榈叶林极显著地高于半湿润常绿榈叶林; 其他类型之间的差异不 显著。非度量多维尺度分析显示, 海拔、坡度、土壤含水率及有机质等 9 个环境梯度是控制森林群落结构和树种分 布的主要因素。土壤有效嗍、海拔、全钾和凹凸度为树种丰富度的最佳预测变量, 累积解释了树种丰富度 $63.2 \%$ 的变异。地形和土壤因子一起能够解释哀牢山常绿榈叶林的群落组成和树种丰富度的大部分变异。
\end{abstract}

关键词: 生境异质性; 群落组成; 树种丰富度; 常绿阔叶林; 哀牢山

\section{Spatial heterogeneity and its causes in evergreen broad-leaved forests in the Ailao Mountains, Yunnan Province}

\author{
Yuanjie $\mathrm{Xu}^{1}$, Dunmei $\mathrm{Lin}^{2}$, Ming Shi ${ }^{3}$, Yanjie Xie ${ }^{3}$, Yizhi Wang ${ }^{1}$, Zhenhua Guan ${ }^{{ }^{*}}$, Jianying Xiang ${ }^{1}$ \\ 1 Yunnan Academy of Biodiversity, Southwest Forestry University, Kunming 650224 \\ 2 Key Laboratory of the Three Gorges Reservoir Region's Eco-Environment, Ministry of Education, Chongqing Universi- \\ ty, Chongqing 400044 \\ 3 The Faculty of Forestry, Southwest Forestry University, Kunming 650224
}

\begin{abstract}
Understanding the variation of species richness over spatial scales, and elucidating the response of plant community composition to habitat heterogeneity has been one of the major topics in the study of community ecology. Niche differentiation related to habitat heterogeneity plays an important role in shaping diversity levels and species distribution patterns of plant communities. Based on a survey of 42 plots of four types of evergreen broad-leaved forests in the Ailao Mountains of Yunnan Province, this paper explored how community distribution and tree species richness of such forests changed along topographic and edaphic gradients. We found significant differences in community composition among the four types of evergreen broad-leaved forests. Tree species richness of monsoon evergreen broad-leaved forests was significantly higher than that of the other forest types. Tree species richness of mid-montane moist evergreen broad-leaved forests was significantly higher than that of semi-humid evergreen broad-leaved forests, whereas no significant difference was observed among the other forest types. Non-metric multidimensional scaling (NMDS) revealed that nine environmental gradients, including elevation, slope, soil water content, soil organic matter, were the determinants of forest community composition and tree distribution patterns. As the best predictors of tree species richness, soil available boron, elevation, soil total potassium and convexity together explained $63.2 \%$ of the variance of tree species richness. The combination of topographic and edaphic factors explained most of the variance of community composition and tree species richness of the evergreen broad leaved forests in the Ailao Mountains.
\end{abstract}

收稿日期: 2016-07-20; 接受日期: 2017-01-05

基金项目: 国家自然科学基金(31300454)

* 通讯作者 Author for correspondence. E-mail: gzhenhua009@gmail.com 
Key words: habitat heterogeneity; community composition; tree species richness; evergreen broad-leaved forests; the Ailao Mountains

局地环境条件和生态系统过程对树种分布和 丰富度格局的影响是植物生态学和生物地理学的 核心议题之一(Poulos \& Camp, 2010), 森林群落中 树种的分布和多度格局反映着树种生态位需求和 种群动态与生境的时空变化相互作用的结果(Urban et al, 2000)。物理环境的空间异质性造成资源可利 用性的水平 (如土壤养分和水分)和垂直(如林冠层 和根系区域)方向上的差异 (Oliveira-Filho et al, 2001; Pinto et al, 2005), 从而可导致树种的生态位 分化, 形成特定的空间分布格局(Palmiotto et al, 2004; Russo et al, 2005)。除了对森林群落结构和树 种组成复杂性产生影响(Pinto et al, 2005)外, 许多 研究还表明生境异质性与树种多样性之间存在正 相关关系(Balvanera \& Aguirre, 2006; Pereira et al, 2007; Lundholm, 2009; Homeier et al, 2010)。多样化 的生境能够支持较高的物种多样性, 这是因为树种 资源利用策略的差异抑制了群落的竞争排除效应 (Balvanera \& Aguirre, 2006), 促成了更大范围的树 种共存(Oliveira-Filho et al, 1994; Itoh et al, 2003; Yasuhiro et al, 2004)。

地形特征及土壤属性是环境异质性的主要决 定因素(Ferreira-Júnior et al, 2007), 对树种多样性和 群落结构具有重要的影响(Potts et al, 2002; Jones et al, 2008; Baldeck et al, 2013)。地形因素是为植物群 落提供生境多样性最重要的环境梯度(Takyu et al, 2002), 森林树种与基于地形属性划分的生境类型 之间存在普遍的关联(Chuyong et al, 2011), 随土壤 养分的变化呈现出非随机分布格局(Baldeck et al, 2013)。局地尺度的研究常以地形变异替代生境异质 性(Baldeck et al, 2013), 这是因为通过调节土壤养 分和水分有效性(Tsui et al, 2004; Yimer et al, 2006; Engelbrecht et al, 2007), 地形因素对树木个体生长、 死亡、更新的动态过程产生影响(Tateno \& Takeda, 2003; Yasuhiro et al, 2004; de Toledo et al, 2011)。土 壤属性对森林的群落结构和树种分布格局起实质 性的作用(Budke et al, 2007; Pinto et al, 2005)。在树 种极其丰富的森林群落中, 超过 $1 / 3$ 的树种分布受 到土壤养分资源的影响(John et al, 2007), 土壤质
地、阳离子构成和碳氮比是森林树种组成的决定因 素(Bohlman et al, 2008)。由于群落结构的复杂性以 及环境因子间的交互作用，树种分布及多样性格局 沿环境梯度变化的机制尚不清楚(Engelbrecht et al, 2007; Homeier et al, 2010)。

常绿润叶林是云南亚热带植被的优势类型，有 着极为广阔的分布地域, 其类型之多样和物种之丰 富为该省多数植被类型所不及(云南植被编写组, 1987)。哀牢山纵贯云南中部，位于我国云贵高原、 横断山地和青藏高原三大自然区域的结合部, 是多 种生物区系地理成分东西交汇、南北过渡之地，保 存着我国亚热带地区面积最大的山地常绿阔叶林 (哀牢山自然保护区综合考察团, 1988)。本文以分布 在哀牢山的4种常绿阔叶林植被亚型一山顶苔藓 矮林、中山湿性、半湿润、季风常绿阔叶林为研究 对象，通过样地调查和取样分析，拟探讨以下问题: (1)4种常绿阔叶林的群落组成和树种丰富度是否存 在显著差异; (2)哪些环境因子与常绿阔叶林树种构 成的空间分异之间存在密切联系; (3)树种丰富度格 局能被哪些关键环境因子所解释。通过揭示常绿阔 叶林群落分布及树种丰富度格局的变化规律, 以及 关键环境梯度的作用和影响, 可为云南常绿阔叶林 资源及其树种多样性的保护提供科学依据。

\section{1 材料与方法}

\section{1 研究区概况}

哀牢山属云岭山脉向南分支的余脉，呈西北往 东南走向, 纵贯云南省中部。根据哀牢山森林生态 系统研究站的长期监测资料, 该区年平均降雨量为 1,931 mm, 雨季(5-10月)降雨量占年降雨量的 $85 \%$ 左右。年平均蒸发量为 $1,485 \mathrm{~mm}$, 年平均温度为 $11.3^{\circ} \mathrm{C}$, 最热月 $\left(7\right.$ 月)平均气温为 $16.4^{\circ} \mathrm{C}$, 最冷月 $(1$ 月)平均气温为 $5.4^{\circ} \mathrm{C}$ 。哀牢山海拔高差达 $2,000 \mathrm{~m}$ 以 上, 气候、植被、土壤沿海拔梯度分异明显。森林 类型丰富多样, 以云南特有种或以云南为分布中心 的树种为优势; 常绿阔叶林有 4 个植被亚型, 即山 顶苔藓矮林、中山湿性、半湿润和季风常绿阔叶林, 以山地黄棕壤和红壤为主要土壤类型(哀牢山自然 
保护区综合考察团, 1988; 巩合德等, 2011)。

\section{2 样地调查}

野外调查取样路线的确定主要参考《云南植 被》(云南植被编写组, 1987) 对常绿阔叶林植被亚型 的划分，以及《哀牢山自然保护区综合考察报告集》 (哀牢山自然保护区综合考察团, 1988)中对山地植 被垂直带谱和常绿阔叶林分布状况的研究结果。山 顶苔藓矮林和中山湿性常绿阔叶林样地设置在哀 牢山森林生态系统研究站附近 $\left(24^{\circ} 32^{\prime} \mathrm{N}, 101^{\circ} 01^{\prime} \mathrm{E}\right)$, 海拔范围2,400-2,700 m; 季风常绿阔叶林样地设置 在镇沅县恩乐镇民江村 $\left(24^{\circ} 03^{\prime} \mathrm{N}, 101^{\circ} 09^{\prime} \mathrm{E}\right)$, 海拔 1,800-1,900 m; 半湿润常绿阔叶林样地设置在新平 县大帽耳山 $\left(24^{\circ} 12^{\prime} \mathrm{N}, 101^{\circ} 25^{\prime} \mathrm{E}\right)$, 海拔2,100-2,200 $\mathrm{m}$ 左右。由于中山湿性常绿阔叶林是哀牢山自然保 护区的主体和精华, 分布最为广泛, 保存最为完整, 所以设置样地数目为 24 个, 其余植被亚型均为 6 个, 共计 42 个(图1)。样地投影面积为 $20 \mathrm{~m} \times 20 \mathrm{~m}$, 借助 于全站仪, 我们还测定了样地顶点及中心的相对高 差, 用于计算地形因子(坡度、坡向、凹凸度)。用 GPS记录每个样地的海拔和经纬度, 测量了样地内 所有木本个体的胸径 $(\geq 1 \mathrm{~cm})$ 。调查时将样地划分为
4 个象限, 在每个象限中心处对表层土 $(0-20 \mathrm{~cm})$ 取 样，混合均匀，风干后以备实验分析。

\section{3 环境因子的测定}

样地海拔为 4 个顶点海拔的平均值; 坡度为样 地任意 3 个顶点组成的平面与水平面夹角的平均值; 坡向为坡面法线在水平面上投影与正北方向的夹 角; 凹凸度为样地中心的海拔减去 4 个顶点海拔的 平均值, 详细算法参照Yamarura等(1995)和 Lai 等 (2009)。数据分析时对坡度数值取正弦, 使之成为 0-1之间的数值; 坡向的转换使用以下公式:

$$
\text { TRASP }=\frac{1-\cos [\pi(\text { aspect }-30) / 180]}{2}
$$

式中 aspect为坡向的角度数值, TRASP为转换后的 坡向数值, 该值越大表明越向阳, 如 1 代表南偏西 $30^{\circ}, 0$ 代表北偏东 $30^{\circ}$ (Xu et al, 2011)。

土壤样品在实验室内处理分析, 共获得 10 项理 化指标。土壤含水量的测定用烘干法, $\mathrm{pH}$ 值用电位 测定法，有机质用重铬酸钾容量-外加热法，全氮用 高氯酸-硫酸消化法, 全磷用酸溶-钿锑抗比色法, 全钾用酸溶-火焰光度法, 有效氮用碱解蒸馏法, 有 效磷采用碳酸氢钠浸提-钿锑抗比色法, 有效钾用

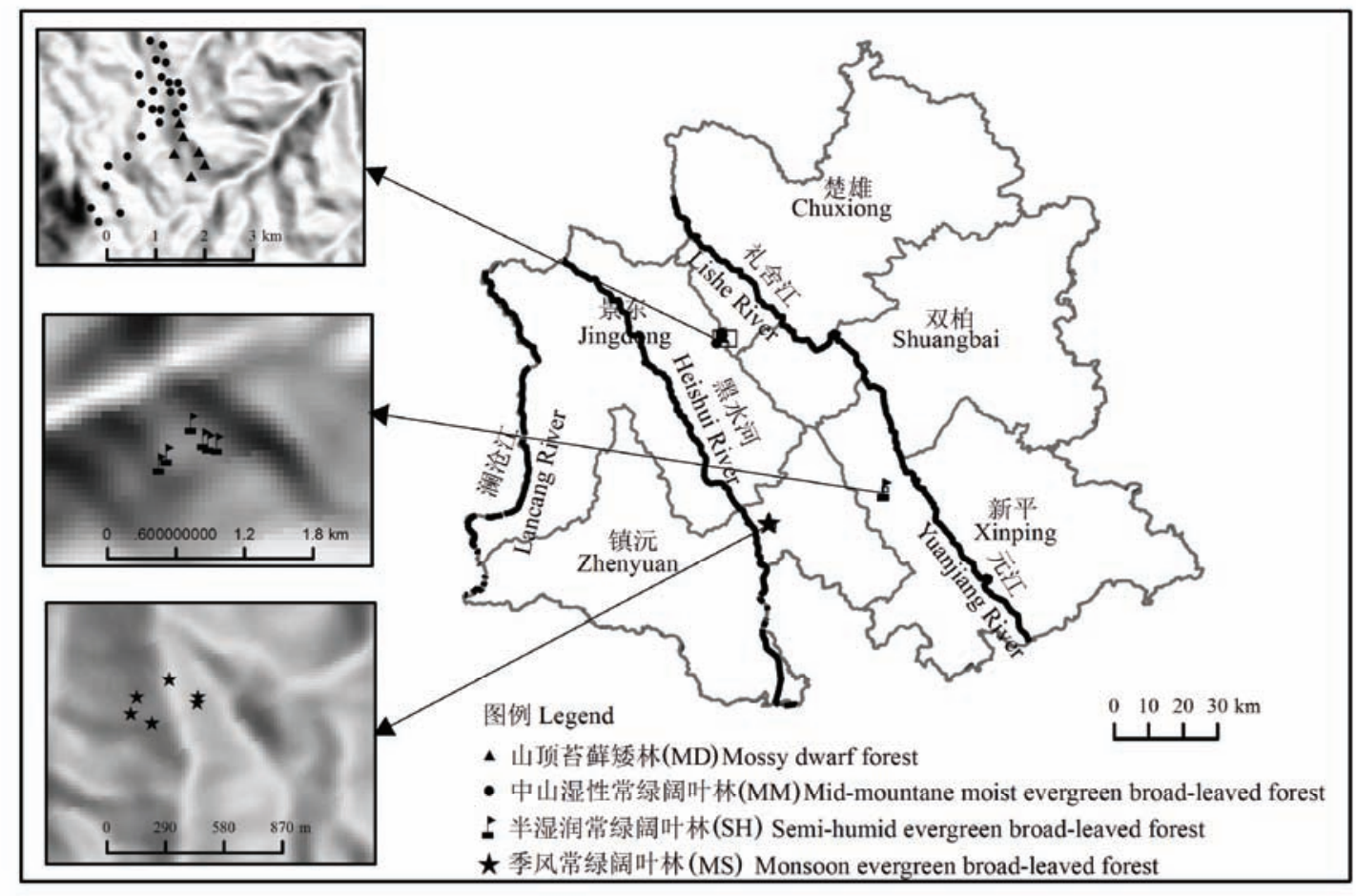

图1 哀牢山和研究区的地理位置

Fig. 1 Location of the Ailao Mountains and overview of the study area 
乙酸铵浸提-火焰光度计法, 有效嗍用甲亚胺 $\mathrm{H}$ 分光 光度法(鲍士旦, 2005)。

\section{4 数据分析}

相对优势度为样地内某树种的胸径截面积之 和占全部树种的胸径截面积总和的比例。用相似性 百分比(similarity percentage, SIMPER)检测对 4 种常 绿阔叶林植被亚型的群落组成差异贡献最大的优 势种, 用非度量多维尺度分析(non-metric multidimensional scaling, NMDS)揭示森林群落在环境梯度 上的分布格局及其关键影响因子。选用Margalef指 数刻画样地的树种丰富度(Magurran, 2004), 采用 Kruskal-Wallis test及Dunn's test检验 4 种植被亚型的 树种丰富度是否存在显著性差异。Dunn's test是一 种非参数多重比较方法, 适用于数据不满足方差齐 性要求时组间数据的两两比较, 往往在KruskalWallis test 检测到显著组间差异后使用(Dinno, 2015)。

为了探究树种丰富度对关键环境因子的响应 以及各个预测变量的解释能力, 我们采取以下分析 过程: (1)以树种丰富度为响应变量, 以全部环境因 子为预测变量, 构建广义可加模型 (generalized addictive model, GAM)。(2)环境因子任意组合, 计算 由此产生的所有模型的 AICc (the second-order Akaike information criterion)值。AICc 为修正后的赤 池信息准则, 适用于样本量较小 $(n / K<40, n$ 为样本 量, $K$ 为参数个数) 时最佳模型的选择 (Peruggia, 2003)。各个模型将按照AICc值的大小排列, AICc值 最小者为最优模型, 并根据AICc的权重值计算相关 环境因子的相对重要性。(3)以树种丰富度为响应变 量, 以入选最优模型的环境因子为预测变量, 重新 构建广义可加模型, 检验模型的解释能力以及入选 环境因子的显著性。(4)最后拟合树种丰富度对入选 环境因子的响应曲线。

相似性百分比分析和多样性指数的计算在 PRIMER 5.0中进行, 其余分析均在R 3.2.5 软件 (www.cran.r-project.org)中完成。䇥选GAM最佳模型 和评估相关环境因子相对重要性时调用了“dredge” 和 “importance” 函数。非度量多维尺度分析、 Kruskal-Wallis 秩和检验以及 Dunn's 多重比较、 “dredge”和“importance”分别在“vegan”、“dunn.test”、 “MuMIn”软件包中完成(Bartoń, 2015; Oksanen et al, 2016; Dinno, 2016)。用“mgcv”软件包(Wood, 2016)
构建广义可加模型、绘制树种丰富度对环境因子的 响应曲线。在进行非度量多维尺度分析时, 对树种 的相对优势度和环境因子分别进行了平方根和标 准化处理。

\section{2 结果}

\section{1 森林群落的树种组成及分布}

42 个森林样地共记录乔木和灌木 (胸径 $\geq 1$ $\mathrm{cm}) 105$ 种, 隶属34科63属。其中较大的科依次为樟 科(7属16种)、壳斗科(4属16种)、山茶科(6属11种)、 菩薇科(7属7种)、杜鹃花科(4属7种)、冬青科(1属7 种)、山矾科(1属6种)和五加科(2属3种)。相似性百 分比分析显示, 苔藓矮林样地特有的优势树种为倒 卵叶石柇(Lithocarpus crassifolius)、云南桤叶树 (Clethra delavayi) 、露珠杜鹃 (Rhododendron irroratum), 珍珠花(Lyonia ovalifolia)、珊瑚冬青(Ilex corallina)和云南越桔(Vaccinium duclouxii)的优势很 明显, 但也是中山湿性常绿阔叶林的优势树种。中 山湿性常绿阔叶林特有的优势树种为木果石栋 (Lithocarpus xylocarpus)、腾冲栲 (Castanopsis wattii)、硬斗柯(Lithocarpus hancei)、薄叶马银花 (Rhododendron leptothrium)、舟柄茶 (Stewartia pteropetiolata)、滇木荷(Schima noronhae)和四川冬 青(Ilex szechwanensis)。季风常绿榈叶林的优势树种 有9种, 主要是早冬瓜(Alnus nepalensis)、高山栲 (Castanopsis delavayi)、母猪果(Helicia nilagirica)、 茶梨(Anneslea fragrans)、截头石栎(Lithocarpus truncatus)、小果栲(Castanopsis fleuryi)、滇南木姜 子(Litsea garrettii)、西南木荷(Schima wallichii)、红 梗润楠(Machilus rufipes)。半湿润常绿阔叶林的树种 较为单一, 其中滇青冈 (Cyclobalanopsis glaucoides)、白穗石栋(Lithocarpus craibianus)、多穗石栋 (L. polystachyus)、旱冬瓜占绝对优势(表1)。

NMDS排序的stress值为 0.091 , 小于 0.1 , 表明 排序效果良好(图2)。海拔、土壤含水率、 $\mathrm{pH}$ 值、有 效硼、有效磷的箭头连线较长, 表明这些预测变量 有着较强的解释能力。其中土壤含水率和 $\mathrm{pH}$ 值的箭 头连线与NMDS第一轴的夹角较小, 表明与其相关 性较高, NMDS第一轴主要展示了土壤含水率和 $\mathrm{pH}$ 值两个梯度; 此外, 海拔、土壤有机质、有效磷与 第一轴呈现出极显著的负相关关系 $(P<0.01)$ 。有效 喼和有效钾与第二轴正相关, 坡度和全钾与第二轴 
表14种常绿阔叶林样地树种相对优势度(\%)及其对组内相似性的贡献率(括号内的数值, \%)

Table 1 Relative dominance (\%) of tree species and their contributions (\%) to within-group similarities. The contributions of different tree species are shown in brackets.

\begin{tabular}{|c|c|c|c|c|}
\hline $\begin{array}{l}\text { 树种名 } \\
\text { Species name }\end{array}$ & $\begin{array}{l}\text { 苔蘚矮林 } \\
\text { MD }\end{array}$ & $\begin{array}{l}\text { 中山湿性润叶林 } \\
\text { MM }\end{array}$ & $\begin{array}{l}\text { 季风常绿阔叶林 } \\
\text { MS }\end{array}$ & $\begin{array}{l}\text { 半湿润常绿阔叶林 } \\
\text { SH }\end{array}$ \\
\hline 倒卵叶石栋 Lithocarpus crassifolius & $25.54(23.40)$ & & & \\
\hline 云南桤叶树 Clethra delavayi & $12.81(17.81)$ & & & \\
\hline 露珠杜鹃 Rhododendron irroratum & $19.47(17.51)$ & & & \\
\hline 云南越桔 Vaccinium duclouxii & $8.37(13.47)$ & $8.68(21.18)$ & & \\
\hline 珍珠花 Lyonia ovalifolia & $10.45(12.52)$ & $9.99(10.38)$ & & \\
\hline 珊瑚冬青 Ilex corallina & $5.94(6.35)$ & $8.50(13.34)$ & & \\
\hline 木果石栎 Lithocarpus xylocarpus & & $16.88(20.10)$ & & \\
\hline 腾冲栲 Castanopsis wattii & & $7.50(7.53)$ & & \\
\hline 硬斗柯 Lithocarpus hancei & & $8.96(6.42)$ & & \\
\hline 薄叶马银花 Rhododendron leptothrium & & $3.30(4.70)$ & & \\
\hline 舟柄茶 Stewartia pteropetiolata & & $3.94(3.51)$ & & \\
\hline 滇木荷 Schima noronhae & & $5.13(2.59)$ & & \\
\hline 四川冬青 Ilex szechwanensis & & $2.72(2.01)$ & & \\
\hline 旱冬瓜 Alnus nepalensis & & & $19.39(21.73)$ & $9.71(18.22)$ \\
\hline 高山栲 Castanopsis delavayi & & & $9.56(21.37)$ & \\
\hline 母猪果 Helicia nilagirica & & & $4.29(10.23)$ & \\
\hline 茶梨 Anneslea fragrans & & & $2.51(8.21)$ & \\
\hline 截头石栎 Lithocarpus truncatus & & & $10.20(7.47)$ & \\
\hline 小果栲 Castanopsis fleuryi & & & 8.93(7.35) & \\
\hline 滇南木姜子 Litsea garrettii & & & $4.37(6.19)$ & \\
\hline 西南木荷 Schima wallichii & & & $6.13(4.77)$ & \\
\hline 红梗润楠 Machilus rufipes & & & $4.96(2.97)$ & \\
\hline 滇青冈 Cyclobalanopsis glaucoides & & & & $35.04(27.95)$ \\
\hline 白穗石栋 Lithocarpus craibianus & & & & 28.38(27.93) \\
\hline 多穗石栋 Lithocarpus polystachyus & & & & 20.47(24.96) \\
\hline
\end{tabular}

MD, Mossy dwarf forest; MM, Mid-mountane moist evergreen broad-leaved forest; MS, Monsoon evergreen broad-leaved forest; SH, Semi-humid evergreen broad-leaved forest.

\section{表2 NMDS排序轴与环境因子的相关性系数}

Table 2 Correlation coefficients of the NMDS ordination axes and the environmental factors

\begin{tabular}{|c|c|c|c|c|}
\hline $\begin{array}{l}\text { 环境因子 } \\
\text { Environmental factors }\end{array}$ & NMDS第一轴 NMDS1 & NMDS第二轴 NMDS2 & $r^{2}$ & $P$ \\
\hline 海拔 Elevation & -0.779 & -0.627 & 0.897 & 0.001 \\
\hline 凹凸度 Convexity & 0.992 & -0.128 & 0.098 & 0.134 \\
\hline 坡向 Aspect & -0.025 & -1.000 & 0.035 & 0.490 \\
\hline 坡度 Slope & -0.352 & -0.936 & 0.241 & 0.007 \\
\hline 土壤含水率 Soil water content (SW) & -0.994 & -0.107 & 0.635 & 0.001 \\
\hline 土壤有机质 Soil organic matter (SOM) & -0.825 & -0.566 & 0.293 & 0.003 \\
\hline 土壤pH值 $\mathrm{pH}$ & 0.998 & 0.067 & 0.597 & 0.001 \\
\hline 全氮 Total nitrogen (TN) & -0.367 & -0.930 & 0.060 & 0.312 \\
\hline 全磷 Total phosphorus (TP) & -0.543 & 0.840 & 0.108 & 0.121 \\
\hline 全钾 Total potassium (TK) & 0.150 & -0.989 & 0.374 & 0.002 \\
\hline 有效氮 Available nitrogen (AN) & -0.582 & 0.813 & 0.079 & 0.210 \\
\hline 有效磷 Available phosphorus (AP) & -0.918 & 0.396 & 0.432 & 0.001 \\
\hline 有效钾 Available potassium (AK) & 0.112 & 0.994 & 0.316 & 0.001 \\
\hline 有效嗍 Available boron (AB) & -0.272 & 0.962 & 0.503 & 0.001 \\
\hline
\end{tabular}

$P$ 值表示环境因子与NMDS第一轴或第二轴相关系数的显著性。 $P$ refers to significant correlation between the environmental variables and either NMDS axis 1 , or NMDS axis 2 . 


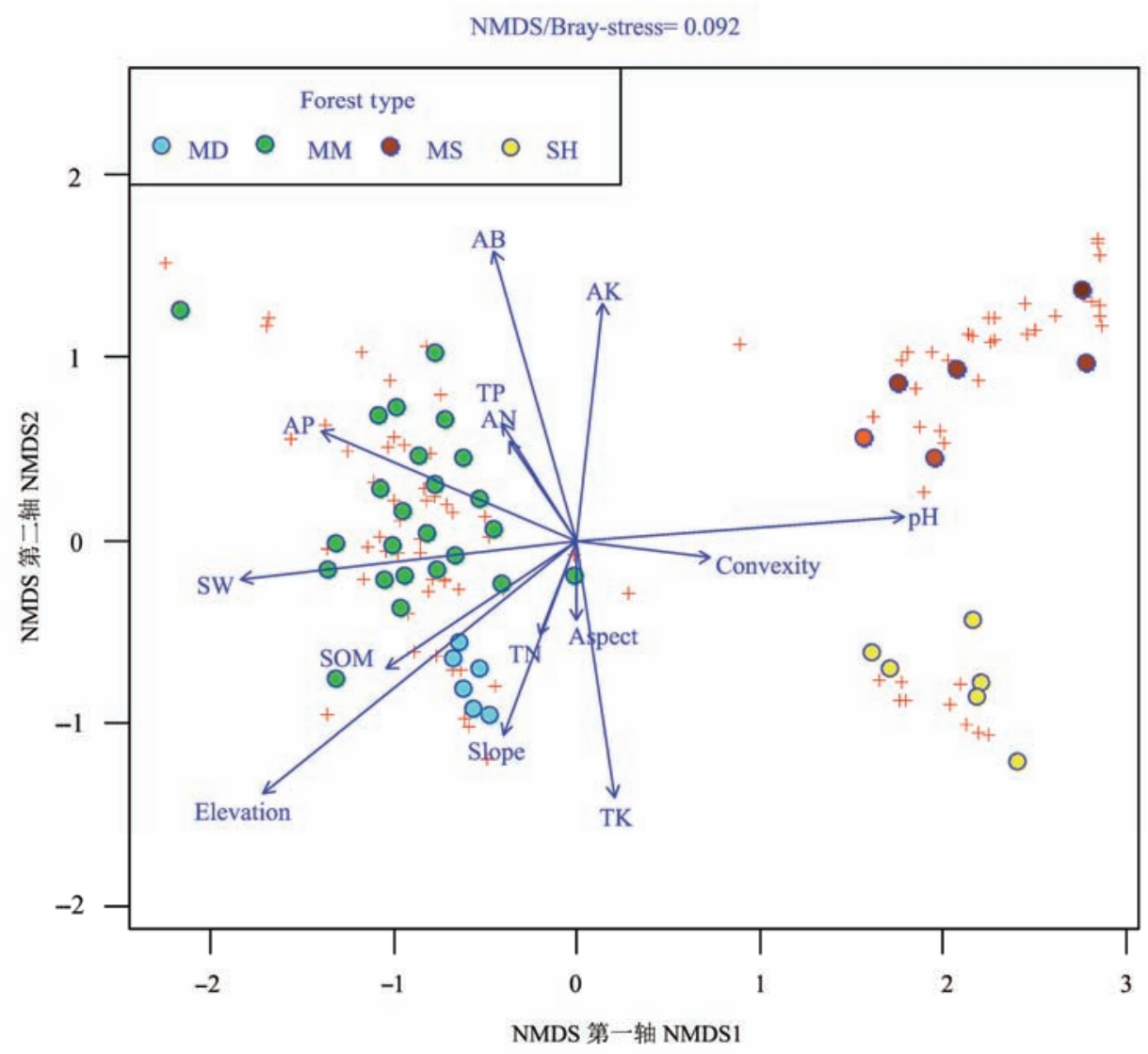

图2 哀牢山4种植被亚型森林样地非度量多维尺度分析。圆圈、+、箭头分别代表样地、树种及环境因子(图注同图1及表2) Fig. 2 Non-metric multidimensional scaling ordination of forest plots (4 vegetation sub-types) in the Ailao Mountains. Colored circles, symbols “+” and arrows indicate plots, tree species and environmental factors respectively. Notes see Fig. 1 and Table 2.

负相关, 均达到极显著水平 (表2)。苔藓矮林样地之 间的距离最近，表明其树种组成有较大的相似性; 而组成季风常绿阔叶林样地的树种差异相对较大。 季风常绿阔叶林和半湿润常绿阔叶林的生境都具 有土壤含水率较低、pH值较高的特征，不同之处在 于季风常绿阔叶林的海拔和土壤有机质含量较低, 而半湿润常绿阔叶林的土壤有效磷和有效硼含量 较低。苔藓矮林位于海拔高、坡度大的地段, 土壤 有机质和全钾含量均较高。中山湿性常绿阔叶林具 有较高的土壤含水率、有效磷含量以及较低的 $\mathrm{pH}$ 值 (图2)。

\section{2 树种丰富度格局及其关键影响因子}

Kruskal-Wallis秩和检验结果表明至少有一种 常绿润叶林的树种丰富度与其他植被亚型存在极 显著差异 $\left(\chi^{2}=22.845, P=0.000\right)$, Dunn's多重比较 进一步显示, 季风常绿阔叶林的树种丰富度极显著 地高于中山湿性常绿阔叶林 $(z=2.463, P=0.007)$ 、
山顶苔藓矮林 $(z=3.177, P=0.001)$ 及半湿润常绿阔 叶林 $(z=4.518, P=0.000)$; 中山湿性常绿阔叶林极 显著地高于半湿润常绿阔叶林 $(z=3.252, P=$ $0.001)$; 中山湿性常绿阔叶林与山顶苔藓矮林 $(z=$ 1.555, $P=0.060$ )以及山顶苔藓矮林与半湿润常绿 阔叶林 $(z=1.341, P=0.090)$ 之间的差异没有达到显 著性水平(图3)。

广义可加模型的篮选结果显示土壤有效硼、海 拔、全钾、凹凸度等 4 个环境因子为树种丰富度格 局的最佳解释变量。“importance”函数的评估结果表 明除以上环境因子外，土壤有效钾和 $\mathrm{pH}$ 值对树种 丰富度也有较大影响(表3)。最佳模型累积解释了树 种丰富度格局 $63.2 \%$ 的变异, 4 个环境因子对树种丰 富度的影响力依次是有效嗍 $(F=19.288, P=$ $0.000)$ 、海拔 $(F=11.973, P=0.001)$ 、全钾 $(F=5.096$, $P=0.030)$ 和凹凸度 $(F=2.859, P=0.099)$ 。其中，有 效硼和海拔达到极显著水平，全钾达到显著水平， 
表3 “dredge”模型篮选表

Table 3 Model selection with the "dredge" function

\begin{tabular}{|c|c|c|c|c|c|c|c|c|c|c|}
\hline & $\begin{array}{l}\text { 有效嗍 } \\
\mathrm{AB}\end{array}$ & $\begin{array}{l}\text { 有效钾 } \\
\mathrm{AK}\end{array}$ & $\begin{array}{l}\text { 凹凸度 } \\
\text { Convexity }\end{array}$ & $\begin{array}{l}\text { 海拔 } \\
\text { Elevation }\end{array}$ & $\mathrm{pH}$ & $\begin{array}{l}\text { 全钾 } \\
\text { TK }\end{array}$ & $\begin{array}{l}\text { 自由度 } \\
\text { df }\end{array}$ & AICc & $\Delta \mathrm{AICc}$ & $\begin{array}{l}\text { 权重值 } \\
\text { Weight }\end{array}$ \\
\hline 1 & 1.796 & & -0.128 & -0.001 & & -0.345 & 5 & 90.0 & 0.00 & 0.261 \\
\hline 2 & 2.082 & & & -0.001 & & -0.250 & 4 & 90.4 & 0.39 & 0.214 \\
\hline 3 & 2.374 & & & -0.001 & & & 4 & 91.0 & 0.95 & 0.162 \\
\hline 4 & 2.001 & -0.005 & -0.124 & -0.002 & & -0.409 & 6 & 91.3 & 1.26 & 0.139 \\
\hline 5 & 2.290 & -0.005 & & -0.002 & & -0.320 & 6 & 91.5 & 1.44 & 0.127 \\
\hline 6 & 2.544 & & & & 0.676 & -0.302 & 5 & 92.0 & 2.00 & 0.096 \\
\hline $\begin{array}{l}\text { 相对重要性 } \\
\text { Importance }\end{array}$ & 1.00 & 0.27 & 0.40 & 0.90 & 0.10 & 0.84 & & & & \\
\hline
\end{tabular}

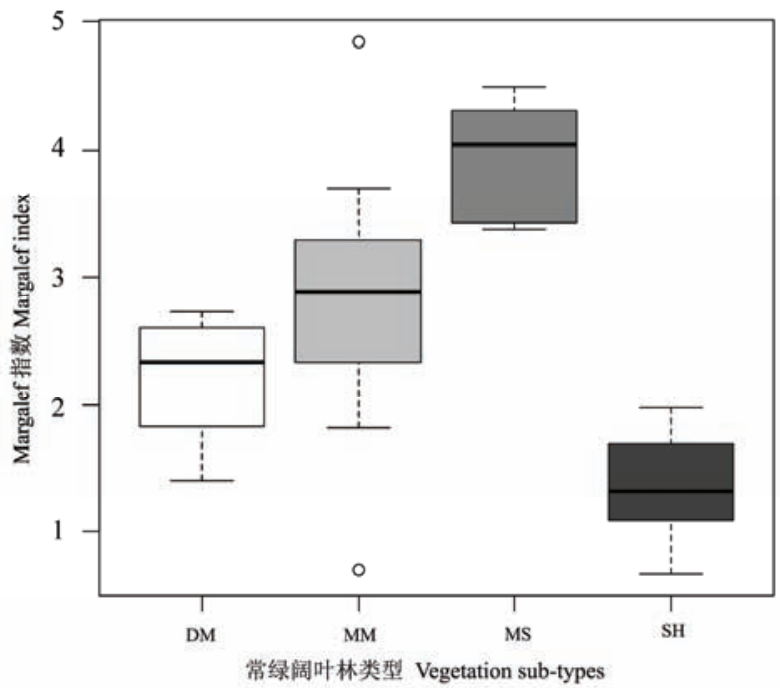

图3哀牢山4种植被亚型森林的树种丰富度。林型代号同图1。 Fig. 3 Tree species richness of four vegetation sub-types in the Ailao Mountains. Forest types see Fig. 1.

凹凸度对模型的影响不显著。具体而言, 树种丰富 度随土壤有效嗍含量的增加而直线上升; 与海拔的 关系是非线性的, 在1,800-2,200 m范围内呈下降趋 势, 并在2,188 m处达到极值, 在2,200-2,500 m范围 内呈上升趋势, 之后又随海拔的升高而下降。树种 丰富度与土壤有效钾之间整体上呈负相关关系，拟 合曲线波动下降。树种丰富度对凹凸度的变异响应 虽未到达显著水平, 但呈现出随之近线性平缓下降 的关系(图4)。

\section{3 讨论}

哀牢山4种常绿阔叶林群落在树种组成和丰富 度格局上均有显著的差异, 非度量多维尺度分析表 明关键环境因子的梯度变化是控制森林群落和树
种分布的主要原因。入选预测树种丰富度格局的最 佳模型的环境因子也是非度量尺度分析揭示的重 要环境梯度, 即土壤有效硼、海拔、全钾和凹凸度。 尽管凹凸度与NMDS第一轴相关系数高达 0.992 , 但 没有达到显著水平 $(P=0.134)$ (表2); 同样在GAM最 佳模型中也未达到显著水平 $(F=2.859, P=0.099)$; 其余3个环境因子的影响都达到了极显著或显著的 水平。影响树种分布和丰富度格局的是同一组环境 因子, 这可能是因为树种对地形和土壤属性的空间 变异产生响应而常常表现出非随机分布的状态 (Clark et al, 1999; Palmiotto et al, 2004; Baldeck et al, 2013), 而树种对特定生境的偏好又是形成树种丰 富度空间变异格局的主要原因(Yasuhiro et al, 2004)。对应于优势树种组成和树种丰富度格局的异 质性，4种常绿阔叶林的生境也呈现出空间分异特 征, 说明生境的分化对局地尺度上的群落构建和多 样性维持具有极其重要的作用(Itoh et al, 2003; Russo et al, 2005; Lundholm, 2009; Chuyong et al, 2011)。

尽管地形变异被认为是控制植被格局和树种 多样性的关键因子(Poulos \& Camp, 2010), 但受地 形因子调节的资源梯度(如土壤养分和太阳辐射)才 是树种分布和森林更新的直接决定因素(Tateno \& Takeda, 2003)。山谷是适宜树木生长的地形, 土层 深厚、水分充足，因而支持了较高水平的树种多样 性(Homeier et al, 2010)。与之相适应的是, 分布在山 谷的树种在获取光资源方面有较强的竞争力，而山 顶树种则更能有效获取土壤氮素(Tateno \& Takeda, 2003)。坡度与森林群落的分布有很强的关系 (Bohlman et al, 2008), 生长在陡坡上的森林群落具 有较高的树种多样性(Guo et al, 2016)。凹凸度是影 

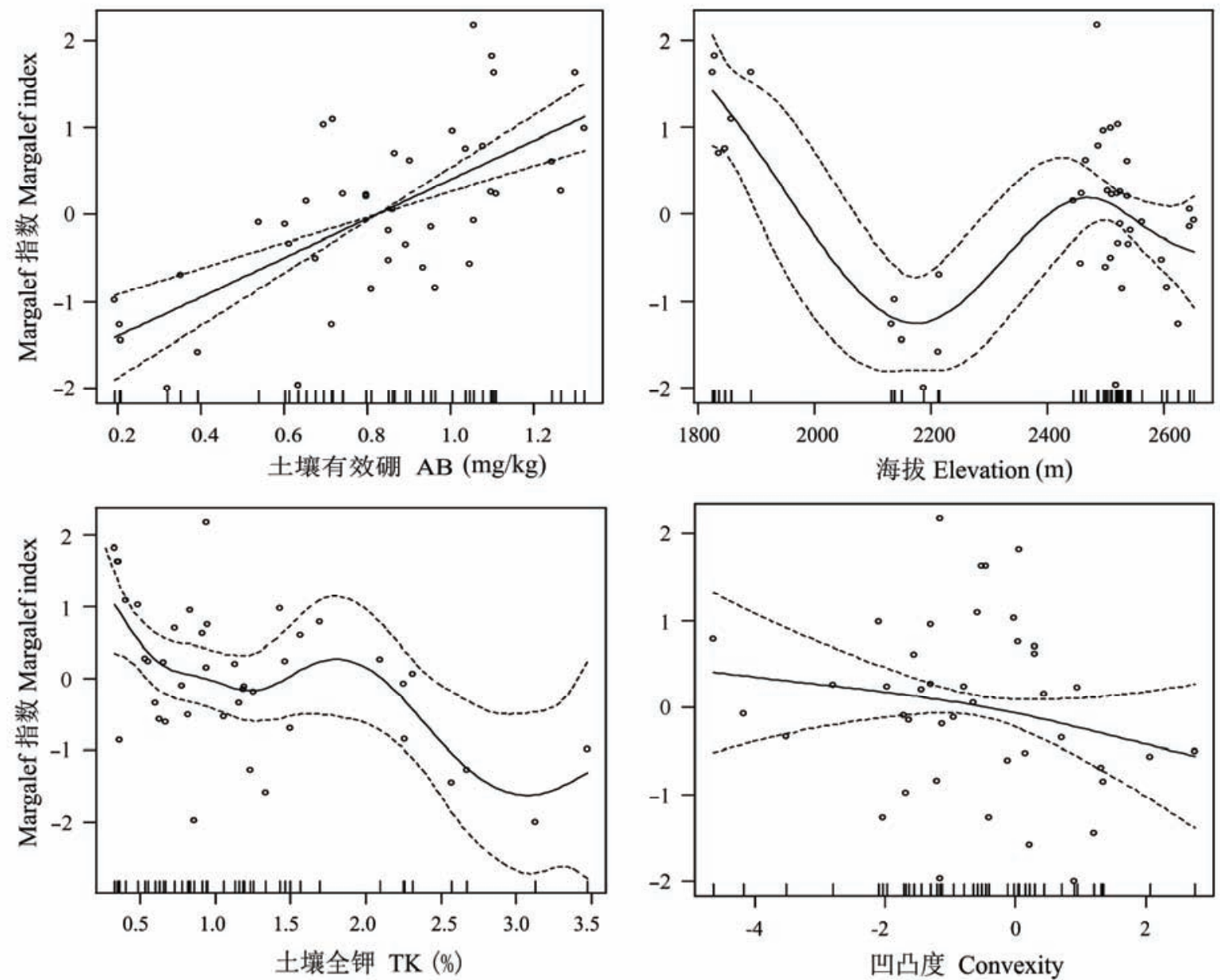

图4 树种丰富度对环境因子的响应。图中实线表示树种丰富度的期望值，虚线表示95\%置信区间。

Fig. 4 Responds of tree species richness to environmental factors. The solid line shows the estimations of tree richness, and the dashed lines indicate 95\% confidence interval.

响土壤水分含量的重要因子, 越小越有利于水分存 留(郭屹立等, 2016), 在本研究中, 凹凸度与树种丰 富度之间呈现出负相关关系, 说明了水分因素的影 响不可忽视。本研究中海拔因子对群落分布、树种 组成及其丰富度格局都有极显著的影响, 但海拔与 丰富度之间并未呈现出确定的关系, 这可能是因为 植物群落物种多样性的海拔格局很大程度上取决 于环境变量之间的协变与互作(Lomolino, 2001)。

树种沿土壤养分资源梯度的生态位分化被认 为是物种极其丰富的森林群落中树种共存的潜在 机制之一(Steidinger, 2015)。稀有种的多样性在土壤 氮磷含量最高时达到峰值, 而常见种的丰富度与土 壤变量无显著相关关系(Laurance et al, 2010)。树种 丰富度是在土壤肥力水平中等或较低时最大(Potts et al, 2002); 本研究中树种丰富度随土壤全钾含量
呈波动下降趋势, 与前人的研究结论一致。土壤钾 素含量对森林的生产力和维持具有重要的作用 (Tripler et al, 2006), 已有研究表明, 过量的土壤钾 素会降低群落水平的细根生物量(Wright et al, 2011)。由于其普遍的稀缺性, 土壤有效嗍是引起树 种生态位分化的一个重要的土壤养分资源轴(John et al, 2007), 树种丰富度与有效硼之间存在正相关 关系(Christensen \& Heilmann-Clausen, 2009), 这一 结论在本研究中得到了验证。值得注意的是, 有效 嗍与树种丰富度之间呈现出线性关系, 而入选最佳 模型的其他 3 个环境因子与树种丰富度之间的关系 为非线性。Steidinger (2015)对Barro Colorado Island 上的193个树种生态位宽度的研究提供了可能的解 释, 即树种对土壤磷和钙的专化利用主要集中在资 源轴的前半段, 也就是说树种针对土壤磷和钙的生 
态位分化只发生在磷和钙含量较低的情况下; 树种 对土壤锰和铝的专化利用主要集中在资源轴的后 半段, 而发生生态位分化的树种在土壤嗍的整个资 源轴上都有分布, 这可能是土壤嗍比其他化学元素 更能对森林群落的组成和结构产生影响的原因。

理解树种沿环境梯度的分布格局是制定森林 保护方案的基础(John et al, 2005), 土壤资源梯度和 地形因素对群落树种组成的变异具有相当的解释 能力(Baldeck et al, 2013)。但目前对于这些格局产生 的机制尚不清楚, 研究具体树种对相关环境变异梯 度的反应是一个重要的途径 (Engelbrecht et al, 2007)。由于所处地理位置的海拔较低, 位于保护区 之外, 哀牢山的季风常绿阔叶林和半湿润常绿阔叶 林普遍遭受到了长期的人为干扰, 如砍伐柇木作为 薪柴、林下放牧等, 从而森林呈现出残存的岛屿状 星散分布。根据本文结果, 季风常绿阔叶林蕴藏着 更为丰富多样的树种; 半湿润常绿阔叶林虽然树种 较为单一, 但是非常独特, 除优势种外, 部分伴生 树种也仅在这一类型中分布, 如金叶子 (Craibiodendron stellatum)、云南栘衣 (Docynia delavayi)、毛杨梅(Myrica esculenta)等。因此, 季风 常绿榈叶林和半湿润常绿阔叶林的保护工作亟需 加强, 这对于保护哀牢山常绿阔叶林和维持生物多 样性具有重要的意义。

致谢: 哀牢山亚热带森林生态系统研究站、哀牢山 国家级自然保护区景东、镇沅、新平管理局提供支 持, 张仲富、陆双飞、张陈刚、鄂保贵等十余人参 与野外调查及样品处理, 米湘成、赖江山、邓建明、 牛明香在数据分析时提供帮助, 实验分析依托 “西 南林业大学大型仪器共享平台 (生物多样性研究院 科研实验平台) ”完成。感谢三位匿名审稿专家提 出的宝贵意见。

\section{参考文献}

Baldeck CA, Harms KE, Yavitt JB, John R, Turner BL, Valencia R, Navarrete H, Davies SJ, Chuyong GB, Kenfack D, Thomas DW, Madawala S, Gunatilleke N, Gunatilleke S, Bunyavejchewin S, Kiratiprayoon S, Yaacob A, Supardi MNN, Dalling JW (2013) Soil resources and topography shape local tree community structure in tropical forests. Proceedings of the Royal Society of London B: Biological Sciences, 280, 20122532.

Balvanera P, Aguirre E (2006) Tree diversity, environmental heterogeneity, and productivity in a Mexican tropical dry forest. Biotropica, 38, 479-491.

Bao SD (2005) Agricultural Chemistry Analysis of Soil. China Agriculture Press, Beijing. (in Chinese) [鲍士旦 (2005) 土 壤农化分析. 中国农业出版社, 北京.]

Bartoń K (2015) MuMIn: Multi-model Inference. R package version, 1.15.6. https://CRAN.R-project.org/package= MuMIn

Bohlman SA, Laurance WF, Laurance SG, Nascimento HE, Fearnside PM, Andrade A (2008) Importance of soils, topography and geographic distance in structuring central Amazonian tree communities. Journal of Vegetation Science, 19, 863-874.

Budke JC, Jarenkow JA, de Oliveira-Filho AT (2007) Relationships between tree component structure, topography and soils of a riverside forest, Rio Botucaraí, Southern Brazil. Plant Ecology, 189, 187-200.

Christensen M, Heilmann-Clausen J (2009) Forest biodiversity gradients and the human impact in Annapurna Conservation Area, Nepal. Biodiversity and Conservation, 18, 2205-2221.

Chuyong GB, Kenfack D, Harms KE, Thomas DW, Condit R, Comita LS (2011) Habitat specificity and diversity of tree species in an African wet tropical forest. Plant Ecology, 212, 1363-1374.

Clark DB, Palmer MW, Clark DA (1999) Edaphic factors and the landscape-scale distributions of tropical rain forest trees. Ecology, 80, 2662-2675.

Comprehensive Investigation Group of the Ailao Mountain National Nature Reserve (1988) Reports on a Comprehensive Investigation of the Ailao Mountain National Nature Reserve. The Nationalities Publishing House of Yunnan, Kunming. (in Chinese) [哀牢山自然保护区综合考察团 (1988) 哀牢山自然保护区综合考察报告集. 云南民族出 版社, 昆明.]

de Toledo JJ, Magnusson WE, Castilho CV, Nascimento HE (2011) How much variation in tree mortality is predicted by soil and topography in Central Amazonia? Forest Ecology and Management, 262, 331-338.

Dinno A (2015) Nonparametric pairwise multiple comparisons in independent groups using Dunn's test. The Stata Journal, 15, 292-300.

Dinno A (2016) Dunn's Test of Multiple Comparisons Using Rank Sums, R package version, 132. https://CRAN.R -project.org/package=dunn.test.

Editorial Committee of the Vegetation of Yunnan (1987) The Vegetation of Yunnan. Science Press, Beijing. (in Chinese) [云南植被编写组 (1987) 云南植被. 科学出版社, 北京.]

Engelbrecht BM, Comita LS, Condit R, Kursar TA, Tyree MT, Turner BL, Hubbell SP (2007) Drought sensitivity shapes species distribution patterns in tropical forests. Nature, 447, 80-82.

Ferreira-Júnior WG, Silva AF, Schaefer CEGR, Neto JAAM, Dias AS, Ignácio M, Medeiros MCMP (2007) Influence of soils and topographic gradients on tree species distribution in a Brazilian Atlantic tropical semideciduous forest. Edinburgh Journal of Botany, 64, 137-157. 
Gong HD, Yang GP, Lu ZY, Liu YH, Cao M (2011) Composition and spatio-temporal distribution of tree seedlings in an evergreen broad-leaved forest in the Ailao Mountains, Yunnan. Biodiversity Science, 19, 151-157. (in Chinese with English abstract) [巩合德, 杨国平, 鲁志云, 刘玉洪, 曹敏 (2011) 哀牢山常绿阔叶林乔木树种的幼苗组成及时空分 布特征. 生物多样性, 19, 151-157.]

Guo YL, Wang B, Xiang WS, Ding T, Lu SH, Huang FZ, Wen SJ, Li DX, He YL, Li XK (2016) Responses of spatial pattern of woody plants' basal area to topographic factors in a tropical karst seasonal rainforest in Nonggang, Guangxi, southern China. Biodiversity Science, 24, 30-39. (in Chinese with English abstract) [郭屹立, 王斌, 向悟生, 丁涛, 陆树华, 黄甫昭, 文淑均, 李冬兴, 何运林, 李先琨 (2016) 喀斯特季节性雨林木本植物胸高断面积分布格局 及其对地形因子的响应. 生物多样性, 24, 30-39.]

Guo YL, Wang B, Mallik AU, Huang FZ, Xiang WS, Ding T, Wen SJ, Lu SH, Li DX, He YL, Li XK (2016) Topographic species-habitat associations of tree species in a heterogeneous tropical karst seasonal rain forest, China. Journal of Plant Ecology, 9, 1-11.

Homeier J, Breckle SW, Günter S, Rollenbeck RT, Leuschner C (2010) Tree diversity, forest structure and productivity along altitudinal and topographical gradients in a species-rich ecuadorian montane rain forest. Biotropica, 42, 140-148.

Itoh A, Yamakura T, Ohkubo T, Kanzaki M, Palmiotto PA, LaFrankie JV, Ashton PS, Lee HS (2003) Importance of topography and soil texture in the spatial distribution of two sympatric dipterocarp trees in a Bornean rainforest. Ecological Research, 18, 307-320.

John R, Dalling JW, Harms KE, Yavitt JB, Stallard RF, Mirabello M, Hubbell SP, Valencia R, Navarrete H, Vallejo M, Foster RB (2007) Soil nutrients influence spatial distributions of tropical tree species. Proceedings of the National Academy of Sciences, USA, 104, 864-869.

Jones MM, Tuomisto H, Borcard D, Legendre P, Clark DB, Olivas PC (2008) Explaining variation in tropical plant community composition: influence of environmental and spatial data quality. Oecologia, 155, 593-604.

Lai JS, Mi XC, Ren HB, Ma KP (2009) Species-habitat associations change in a subtropical forest of China. Journal of Vegetation Science, 20, 415-423.

Laurance SG, Laurance WF, Andrade A, Fearnside PM, Harms KE, Vicentini A, Luizão RC (2010) Influence of soils and topography on Amazonian tree diversity: a landscape-scale study. Journal of Vegetation Science, 21, 96-106.

Lomolino MV (2001) Elevation gradients of species-density: historical and perspective views. Global Ecology and Biogeography, 10, 3-13.

Lundholm JT (2009) Plant species diversity and environmental heterogeneity: spatial scale and competing hypotheses. Journal of Vegetation Science, 20, 377-391.

Magurran AE (2004) Measuring Biological Diversity. Blackwell Science Ltd., Blackwell Publishing Company, Victoria,
Australia.

Oksanen J, Blanchet FG, Kindt R, Legendre P, Minchin PR, O’Hara RB, Simpson GL, Solymos P, Stevens MHH, Wagner H (2016) Vegan: Community Ecology Package, Version 2.3-5. https://CRAN.R-project.org/package=vegan (accessed on 2017-2-3).

Oliveira-Filho AT, Vilela EA, Carvalho DA, Gavilanes ML (1994) Effects of soils and topography on the distribution of tree species in a tropical riverine forest in south-eastern Brazil. Journal of Tropical Ecology, 10, 483-508.

Oliveira-Filho AD, Curi N, Vilela EA, Carvalho DA (2001) Variation in tree community composition and structure with changes in soil properties within a fragment of semi-deciduous forest in south-eastern Brazil. Edinburgh Journal of Botany, 58, 139-158.

Palmiotto PA, Davies SJ, Vogt KA, Ashton MS, Vogt DJ, Ashton PS (2004) Soil-related habitat specialization in dipterocarp rain forest tree species in Borneo. Journal of Ecology, 92, 609-623.

Pereira JAA, Oliveira-Filho AT, Lemos-Filho JP (2007) Environmental heterogeneity and disturbance by humans control much of the tree species diversity of Atlantic montane forest fragments in SE Brazil. Plant Conservation and Biodiversity, 16, 1761-1784.

Peruggia M (2003) Model selection and multimodel inference: a practical information-theoretic approach. Journal of the American Statistical Association, 98, 778-779.

Pinto JRR, Oliveira-Filho AT, Hay JDV (2005) Influence of soil and topography on the composition of a tree community in a central Brazilian valley forest. Edinburgh Journal of Botany, 62, 69-90.

Potts MD, Ashton PS, Plotkin JB, Kaufmann LS (2002) Habitat patterns in tropical rainforests: a comparison of 105 plots in northwest Borneo. Ecology, 83, 2782-2797.

Poulos HM, Camp AE (2010) Topographic influences on vegetation mosaics and tree diversity in the Chihuahuan Desert Borderlands. Ecology, 91, 1140-1151.

Russo SE, Davies SJ, King DA, Tan S (2005) Soil-related performance variation and distributions of tree species in a Bornean rain forest. Journal of Ecology, 93, 879-889.

Steidinger B (2015) Qualitative differences in tree species distributions along soil chemical gradients give clues to the mechanisms of specialization: why boron may be the most important soil nutrient at Barro Colorado Island. New Phytologist, 206, 895-899.

Takyu M, Aiba S, Kitayama K (2002) Effects of topography on tropical lower montane forests under different geological conditions on Mount Kinabalu, Borneo. Plant Ecology, 159, 35-49.

Tateno R, Takeda H (2003) Forest structure and tree species distribution in relation to topography-mediated heterogeneity of soil nitrogen and light at the forest floor. Ecological Research, 18, 559-571.

Tripler CE, Kaushal SS, Likens GE, Walter TM (2006) Patterns in potassium dynamics in forest ecosystems. Ecology Letters, 9, 451-466. 
Tsui CC, Chen ZS, Hsieh CF (2004) Relationships between soil properties and slope position in a lowland rain forest of southern Taiwan. Geoderma, 123, 131-142.

Urban DL, Miller C, Halpin PN, Stephenson NL (2000) Forest gradient response in Sierran landscapes: the physical template. Landscape Ecology, 15, 603-620.

Wood S (2016) Mixed GAM Computation Vehicle with GCV/AIC/REML Smoothness Estimation, Version 1.8-12. https://CRAN.R-project.org/package=mgcv (accessed on 2017-2-3).

Wright SJ, Yavitt JB, Wurzburger N, Turner BL, Tanner EV, Sayer EJ, Santiago LS, Kaspari M, Hedin LO, Harms KE, Garcia MN, Corre MD (2011) Potassium, phosphorus, or nitrogen limit root allocation, tree growth, or litter production in a lowland tropical forest. Ecology, 92, 1616-1625.

Xu YJ, Chen YN, Li WH, Fu AH, Ma XD, Gui DW, Chen YP (2011) Distribution pattern of plant species diversity in the mountainous region of Ili River Valley, Xinjiang. Environ- mental Monitoring and Assessment, 177, 681-694.

Yamakura T, Kanzaki A, Itoh T, Ohkubo K, Ogino EOK, Chai HS, Ashton PS (1995) Topography of a large-scale research plot established within a tropical rain forest at Lambir, Sarawak. Tropics, 5, 41-56.

Yasuhiro K, Hirofumi M, Kihachiro K (2004) Effects of topographic heterogeneity on tree species richness and stand dynamics in a subtropical forest in Okinawa Island, southern Japan. Journal of Ecology, 92, 230-240.

Yimer F, Ledin S, Abdelkadir A (2006) Soil property variations in relation to topographic aspect and vegetation community in the south-eastern highlands of Ethiopia. Forest Ecology and Management, 232, 90-99. 